\title{
Eventual role of asymptomatic cases of dengue for the introduction and spread of dengue viruses in non-endemic regions
}

\author{
Claude Chastel * \\ Laboratoire de Virologie, Faculté de Médecine et des Sciences de la Santé, Brest, France
}

\section{Edited by:}

Rubén Bueno-Mari, University of

Valencia, Spain

Reviewed by:

Sudipto Saha, Case Western Reserve University, USA

Miguel Julian Martinez, Hospital

Clinic i Provincial de Barcelona, Spain

${ }^{*}$ Correspondence:

Claude Chastel, Laboratoire de

Virologie, Faculté de Médecine et des

Sciences de la Santé, 22, Avenue

Camille Desmoulins, F- 29 238,

Brest Cedex 3, France.

e-mail: chastelc@aol.com
In dengue virus infections the asymptomatic cases are much more frequent than the symptomatic ones, but their true role in the introduction and subsequent spread of dengue viruses in non-endemic regions remains to de clarified. We analyzed data from English and French literatures to assess if viremia in asymptomatic dengue infections might be sufficient to represent a true risk. During outbreaks of dengue a large number of individuals are infected and since viremia levels in symptomatic patients are known to vary by many orders of magnitude, it is reasonable to augur that a proportion of asymptomatic cases might reach levels of viremia sufficient to infect competent mosquitoes. In addition, a number of new ways of contamination in man by dengue viruses were recently described such as blood transfusion, bone marrow transplantation, and nosocomial infections that may be worth considering.

Keywords: dengue virus infection, infected travelers, asymptomatic infections, viremia, disease severity

\section{INTRODUCTION}

During the three past decades dengue fever (DF) has shown an unprecedented geographic expansion whilst the annual number of cases and the severity of the disease increased dramatically. This mosquito-borne disease is at present the first arboviral disease infecting mankind worldwide. An estimated 2.5 billion persons live in virus endemic areas and 50-100 million cases occur each year, inducing 500,000 hospitalizations (Halsitead, 2007) and about 20,000 deaths (Strait et al., 2011).

As a direct consequence of the recent establishment of the Aedes albopictus mosquito in many European countries where imported cases of dengue occur among travelers returning from endemic areas, European Union Member States are at risk of local outbreaks. This is particularly evident for Northern Italy (Rovida et al., 2011) and above all for Southern France (Laruche et al., 2010) and Croatia (Gjenero-Margan et al., 2011). In each of these last two countries two autochthonous cases of dengue occurred in September 2010. These few cases were efficiently detected as a result of the recent implementation of European surveillance programs in France, Croatia, and Germany. It is the first time that autochthonous transmission of dengue viruses was recorded in Europe since the historical Greek outbreak of 1927-1928 (Chastel, 2009).

Increased global movement of humans, plants, and hematophagous arthropods via shipping and air traffic has multiplied the opportunities for infected travelers and other items to export dengue viruses from tropical to temperate regions (Chastel, 2007). Whether or not global climate change has worsened the situation is debatable (Reiter, 2001; Chastel, 2002; Barklay, 2008; Gould and Higgs, 2009) but it can no longer be ignored.

Moreover, in dengue as in other mosquito-borne arbovirus infections (Chastel, 2011) the asymptomatic cases are much more frequent than the symptomatic ones although their true role in introduction and subsequent spread of dengue viruses in non-endemic regions remains to be clarified.

This short review therefore examines the concept that asymptomatic disease is an increasingly contributor to the dispersal of dengue viruses than it may have been previously thought.

\section{METHODS}

We have collected pertinent data from English and French literatures from the 1980s to 2011 through PubMed and other bibliographic sources including Dengue Net. Data were analyzed to assess if viremia in asymptomatic dengue infections (dengue 1-4 viruses) might be sufficient to represent a true risk for the introduction of these viruses in non-endemic regions. The key-words we used in searching in databases were: "dengue virus infections," "introduction by infected travelers," "asymptomatic infections," "viremia," and "disease severity." We thus selected five articles dealing with the frequency of asymptomatic cases and seven articles related to viremia in symptomatic or asymptomatic cases. In addition we have taken in account both the classical way of transmission, i.e., by mosquito bite, and the new ones recently documented such as blood transfusion, organ transplantation, needle stick injury, or intrapartum.

Moreover, some studies concerning the introduction of dengue viruses in new areas and the Public Health measures implemented to fight against the consequences of such events were analyzed (see Beckett et al., 2005; Shu et al., 2005; Shang et al., 2010, for instance).

\section{RESULTS}

\section{ATTEMPTS TO MINIMIZE THE INTRODUCTION AND SPREAD OF DENGUE VIRUSES IN NEW AREAS}

It is almost impossible to intercept asymptomatic or mildly symptomatic travelers arriving from tropical regions and entering a 
non-endemic one. However, it is important to emphasize that mild symptoms are a very common feature of arboviruses including the four dengue viruses (DENV 1-4).

In order to detect potential imported cases of DF and thereby to reduce the local spread of the introduced viruses, the Taiwanese Disease Control authorities established an integrated control program that included a variety of surveillance systems, capable of screening for fever in arriving passengers, a network of rapid diagnostic laboratories, and other integrated control measures. This strategy applied between July 2003 and June 2004 identified 40 confirmed cases of DF, all of which were viremic when tested by RT-PCR (Shu et al., 2005). Thus, although it proved costly to implement, this strategy appeared efficient and may be cost effective in long-term.

However, for other authors infrared skin thermometry did not appear an effective tool for the detection of febrile patients (Hausfater et al., 2008). More importantly this technique would not detect asymptomatic individuals.

\section{QUANTIFICATION OF ASYMPTOMATIC CASES IN DENGUE VIRUS INFECTIONS}

In these diseases, the asymptomatic cases are much more frequent than the symptomatic ones, but their relative number varies according to the geographic area, the epidemiologic context, the immunological status of patients, and the circulating type(s) of DENV. This is clearly exemplified by different surveys.

During a prospective survey carried out in 1980-1981 in Bangkok, Thailand, amongst school children, the authors estimated the ratio of asymptomatic/symptomatic cases to be 6.1:1. This ratio was refined to 5.5:1 for DENV 1 infections and 4.5:1 for DENV 2 cases. In addition, the three DENV 4 infections that were detected during this survey were entirely asymptomatic (Burke et al., 1988). In contrast, another prospective study was conducted in Kamphaeng Phet, Northern Thailand, between 1998 and 2000 and the results were quite different since the ratio was only 1.1:1 (Endy et al., 2002).

However, in Nicaragua, Central America, a similar survey carried out between 2001 and 2003 amongst 4- to 16-years-old school children living in Managua city showed that in 2001, when DENV 2 was prevalent, a ratio of 13:1 was determined. In 2002 this ratio fell to 6:1 when DENV 1 was the most frequently isolated serotype (Balmaseda et al., 2006).

In Singapore, South-East Asia, Health authorities assumed a ratio of asymptomatic/symptomatic infections between 2:1 and 10:1. This was considered to represent a very serious threat for blood transfusion recipients (Wilder-Smith et al., 2009).

Finally, amongst Dutch travelers infected between October 2006 and September 2007 in different tropical countries a ratio of 1.8:1 was observed. In this study the type of infecting DENV was not determined since only serologic testing was performed (Baaten et al., 2011).

Thus, according to these surveys, the ratio of asymptomatic/symptomatic cases of dengue virus infection may extensively vary. These differences might be explained by individual variations in susceptibility or variability in the virulence of DENV strains (Balmaseda et al., 2006). Alternatively the epidemiology of dengue may differ in South-East Asia and the Americas (Halstead, 2006).

\section{WHAT ARE THE RISKS ASSOCIATED WITH ASYMPTOMATIC DENGUE VIRUS INFECTIONS?}

In non-endemic regions, it is well established that DENV are being introduced by viremic travelers returning from endemic or epidemic areas, although whether or not they subsequently cause outbreaks depends on a number of crucial requisites: firstly, the infected traveler should be sufficiently viremic to be capable of infecting local mosquitoes; secondly, this mosquito would need to be a highly competent species and sufficiently abundant at the time of virus introduction to ensure its diffusion; thirdly, the local population would need to be highly receptive to DENV. Finally, favorable meteorological conditions represent critic factors for initiating local dengue epidemics in Taiwan (Shang et al., 2010).

Moreover, in both endemic and non-endemic regions, we know that blood transfusion, organ transplantation, and needle stick injuries represent new identified risks of infection by DENV (Hirch et al., 1990; de Wazières et al., 1998; Rigan-Perez et al., 2001; Langgartner et al., 2002; Chen and Wilson, 2004; Nemes et al., 2004; Wagner et al., 2004; Wilder-Smith et al., 2009). Intrapartum is another unusual route of contamination by DENV (Hirch et al., 1990; Rigan-Perez et al., 2001; Tran and Chastel, 2008). All these atypical ways of contamination may originate in a silent infection, either pre-clinic, very mild, or totally asymptomatic. In our opinion, these new modes of contamination greatly increase the opportunities for introduction of DENV in non-endemic regions by asymptomatic individuals.

\section{MAGNITUDE OF VIREMIA IN ASYMPTOMATIC CASES OF DENGUE VIRUS INFECTIONS}

To accurately appreciate the eventual role of asymptomatic cases for the introduction and spread of DENV in non-endemic regions, it is necessary to try to quantify the level of viremia in such infected persons. This is a basic, presently poorly documented problem.

Indeed, even though asymptomatic cases predominate during epidemics, the precise levels of viremia in such cases remain to be evaluated.

There are two studies using virological methods and taking up the problem of the viremia in asymptomatic cases of dengue infections.

The first was conducted, in 2001-2003, in West Jakarta, Indonesia, and showed that viremia might be detected in asymptomatic cases by RT-PCR or virus isolation: on day 10 during a DENV 1 infection in one individual and in day 4 during a DENV 2 infection in another one. Unfortunately, the RT-PCR method used in this study was only qualitative and thus the precise level of viremia was not established (Beckett et al., 2005).

The second study was performed during the 2006 and 2007 epidemics in Kampong Cham, Cambodia. Using NS1 antigen capture, real time RT-PCR, and MAC-ELISA assays, dengue infection was confirmed in 243 symptomatic patients and in 17 asymptomatic family-related individuals. All four dengue serotypes were identified. As this study was essentially devoted to assess if the NS1 antigenemia might represent a good early marker of the disease severity, it is difficult to precisely evaluate the levels of viremia in asymptomatic cases. In fact, the authors stated that "the level of viremia in asymptomatic cases was not significantly lower in asymptomatic cases than in all dengue confirmed cases $(p=0.145)$ " (Duong et al., 2011). 
These scarce and partial results force us to use data established in symptomatic cases to better evaluate the viremia levels in asymptomatic ones.

\section{MAGNITUDE OF VIREMIA IN SYMPTOMATIC CASES OF DENGUE VIRUS INFECTIONS}

During a severe outbreak of DF in French Polynesia during 1996 and 1997, the plasma DENV 2 titers ranged from 1.7 to $5.6 \log 10$ $\mathrm{TCID}_{50} / \mathrm{ml}$ in hospitalized children and the mean duration of the viremia was 4.4 days (Murgue et al., 2000).

In Thailand, viremia titers were determined in 168 children with acute dengue virus infections (DENV 1-4) and two different hospitals (Vaughn et al., 2000). Duration of viremia ranged from 1 to 7 days and the higher mean titer was $10^{7.6} \mathrm{MID}_{50} / \mathrm{ml}$ median mosquito infectious dose (MID) for patients with DF versus $10^{8.5}$ $\mathrm{MID}_{50} / \mathrm{ml}$ for patients with hemorrhagic fever. Thus, the severity of the disease was, in this study, clearly associated with the higher titers of viremia.

The same observation was done in Taiwan during a DENV 3 epidemic in 1998. A total of 20 patients, 11 with DF and 9 with dengue hemorrhagic fever (DHF) were studied using a quantitative RT-PCR. The viremia was found under the detection threshold of the method ( $<600$ RNA copies $/ \mathrm{ml}$ ) in five of the DF patients and between 3,900 and 3,710,000 RNA copies/ml in six others. In contrast, in nine DHF patients the viremia levels extended from 46,700 to $14,900,000$ RNA copies $/ \mathrm{ml}$. These high levels of plasma RNA persisted during defervescence in DHF patients whilst they declined to a level below detection in DF patient. DENV persisting in plasma during defervescence were into immune complexes in most DHF patients (Wang et al., 2003).

Another survey was carried out amongst 80 Thai children using a RT-PCR method able to quantify all the four DENV serotypes. Plasma RNA levels ranged between $5 \times 10^{3}$ and $5 \times 10^{9}$ copies $/ \mathrm{ml}$ (Sudiro et al., 2001).

In Singapore, Public Health authorities estimate DENV plasma viral RNA levels ranging from $10^{5.5}$ to $10^{9.3}$ copies $/ \mathrm{ml}$ (Wilder-Smith et al., 2009). They also suggested: "it is likely, although not proven, that viremia is lower and shorter in duration

\section{REFERENCES}

Baaten, G. G. G., Sonder, G. J. B., Zaaijer, H. L., van Gool, T., Kint, J. A., and van den Hoek, A. (2011). Travel-related dengue virus infections, the Netherlands, 2006-2007. Emerg. Infect. Dis. 17, 821-827.

Balmaseda, A., Hammond, S. N., Tellez, Y., Imhoff, L., Rodriguez, Y., Saborío, S. I., Mercado, J. C., Perez, L., Videa, E., Almanza, E., Kuan, G., Reyes, M., Saenz, L., Amador, J. J., and Harris, E. (2006). High seroprevalence of antibodies against dengue virus in a prospective study of schoolchildren in Managua, Nicaragua. Trop. Med. Int. Health 11, 935-942.

Barklay, E. (2008). Is climate change affecting dengue in Americas? Lancet 371, 973-974.
Beckett, G. G., Kosasih, H., Faisal, I., Nurhayati, Tan, R., Widjaja, S., Listiyaningsih, E., Ma'Roef, C., Wuryadi, S., Bangs, M. J., Samsi, T. K., Yuwono, D., Hayes, C. G., and Porter, K. R. (2005). Early detection of dengue infections using cluster sampling around index cases. Am. J. Trop. Med. Hyg. 72, 777-782.

Burke, D. S., Nisalak, A., Johnson, D. E., and Scott, R. M. (1988). A prospective study of dengue infections in Bangkok. Am. J. Trop. Med. Hyg. 38, 172-180.

Chastel, C. (2002). Expected threats of global climate change on mosquitoand tick-borne arbovirus infections. Bull. Acad. Natl. Med. 186, 89-101.

Chastel, C. (2007). Global threats for emerging viral diseases.

in asymptomatic persons than in symptomatic persons." In the absence of any systematic study in this field such opinion can only be speculative.

On the contrary, it seems reasonable to assume that some asymptomatic cases must achieve viremia levels as high as the lowest estimates for symptomatic cases. In fact, from the above data it is evident that the viremic levels in DF patients are both highly variable and geographically widely dispersed. Therefore it is entirely reasonable to hypothesize that similar dispersion and high variability of virus titers might be present in asymptomatic individuals.

Taking this to the next logical step, if a competent mosquito vector such as A. albopictus is already established in non-endemic regions, for instance Southern Europe, the risk that asymptomatic dengue virus infection could provide the source of new foci of disease or eventually epidemics is likely. Moreover, the existence of atypical ways of contamination reinforce the probability of such a scenario.

\section{CONCLUSION}

Dengue virus infections cause asymptomatic infections much more frequently than symptomatic cases, sometimes multiplying up to 14 the actual number of infections, but their true role in the introduction and subsequent spread of DENV in non-endemic regions remains to be clarified.

Since very large numbers of individuals are infected and since viremic levels are known to vary by several orders of magnitude in symptomatic patients it is reasonable to argue that at least a proportion of asymptomatic cases might reach levels of viremia sufficient to infect competent mosquito vectors.

In addition, the existence of newly recognized ways of contamination in man such blood transfusion, bone marrow transplantation, and nosocomial infections offer other opportunities for DENV to be introduced and spread in non-endemic regions.

More virological studies are needed on asymptomatic cases of dengue to valid or not these hypotheses.

Bull. Acad. Natl. Med. 191, 1563-1577.

Chastel, C. (2009). Lessons from the Greek dengue epidemic of 1927-1928. Bull. Acad. Natl. Med. 193, 485-493.

Chastel, C. (2011). Asymptomatic infections in man: a Trojan horse for the introduction and spread of mosquito-borne arboviruses in nonendemic areas? Bull. Soc. Pathol. Exot. 104, 213-219.

Chen, L. H., and Wilson, M. E. (2004). Transmission of dengue virus without a mosquito vector: nosocomial muco-cutaneous transmission and other routes of transmission. Clin. Infect. Dis. 39, 56-60.

de Wazières, B., Gil, H., Vuitton, D. A., and Dupond, J.-L. (1998). Nosocomial transmission of dengue from a needlestick injury. Lancet 351 , 498.

Duong, V., Ly, S., Lorn Try, P., Tuiskunen, A., Ong, S., Chroeung, N., Lundkvist, A., Leparc-Goffart, I., Deubel, V., Vong, S., and Buchy, P. (2011). Clinical and virological factors influencing the performance of NS1 antigencapture assay and potential use as a marker of dengue disease severity. PLoS Negl. Trop. Dis. 5, e1244. doi:10.1371/journal.pntd.0001244

Endy, T. P., Chunsuttiwat, S., Nisalak, A., Libraty, D. H., Green, S., Rothman, A. L., Vaughn, D. W., and Ennis, F. A. (2002). Epidemiology of inapparent and symptomatic acute dengue virus infection: a prospective study of primary school children in Kamphaeng Phet, Thailand. Am. J. Epidemiol. 156, 40-51. 
Gjenero-Margan, I., Aleraj, B., Krajčar, D., Lesnikar, V., Klobučar, A., PemNovosel, I., Kurečić-Filipović, S., Komparak, S., Martić, R., Duričić, S., Betica-Radić, L., Okmadžić, J., Vilibić-Čavlek, T., Babić-Erceg, A., Turković, B., Avsić-Županc, T., Radić, I., Ljubić, M., Sarac, K., Benić, N., and Mlinarić-Galinović, G. (2011). Autochthonous dengue fever in Croatia, August-September 2010. Euro Surveill. 16, 19805.

Gould, E. A., and Higgs, S. (2009). Impact of climate change and other factors on emerging arbovirus diseases. Trans. R. Soc. Trop. Med. Hyg. 103, 109-121.

Halsitead, S. B. (2007). Dengue. Lancet 370, 1644-1652.

Halstead, S. B. (2006). Dengue in the Americas and in Southeast Asia: do they differ? Rev. Panam. Salud Publica 20, 407-415.

Hausfater, P., Zhao, Y., Defrenne, S., Bonnet, P., and Riou, B. (2008). Cutaneous infrared thermometry for detecting febrile patients. Emerg. Infect. Dis. 14, 1255-1257.

Hirch, J. F., Descamps, C., and Lhuillier, M. (1990). Transmission métropolitaine d'une dengue par inoculation accidentelle hospitalière. Ann. Med. Interne (Paris) 141, 629.

Langgartner, J., Audebert, F., Schömerich, J., and Glück, T. (2002). Dengue virus infection transmitted by needle stick injury. $J$. Infect. 44, 269-270.

Laruche, G., Souarès, Y., Armengaud, A., Peloux-Petiot, F., Delaunay, P., Desprès, P., Lenglet, A., Jourdain, F., Leparc-Goffart, I., Charlet, F., Ollier,
L., Mantey, K., Mollet, T., Fournier, J. P., Torrents, R., Leitmeyer, K., Hilairet, P., Zeller, H., Van Bortel, W., Dejour-Salamanca, D., Grandadam, M., and Gastellu-Etchegorry, M. (2010). First two autochthonous dengue virus infections in metropolitan France, September 2010. Euro Surveill. 15, 19676.

Murgue, B., Roche, C., Chungue, E., and Deparis, X. (2000). Prospective study of viraemia in children hospitalised during the 1996-1997 dengue-2 outbreak in French Polynesia. J. Med. Virol. 60, 432-438.

Nemes, Z., Kiss, G., Maradassi, E. P., Peterfi, Z., Ferenczi, E., Bakonyi, T., and Ternak, G. (2004). Nosocomial transmission of dengue. Emerg. Infect. Dis. 10, 1880-1881.

Reiter, P. (2001). Climate change and mosquito-borne diseases. Environ. Health Perspect. 109(Suppl. 1), 141-161.

Rigan-Perez, J. G., Vomdam, A. V., and Clark, G. G. (2001). The dengue and dengue hemorrhagic fever epidemic in Puerto Rico, 1994-1995. Am. J. Trop. Med. Hyg. 64, 67-74.

Rovida, F., Percivalle, E., Campannini, G., Piralla, A., Novati, S., Muscatello, A., and Baldanti, F. (2011). Viremic dengue virus infections in travellers: potential for local outbreak in Northern Italy. J. Clin. Virol. 50. doi:10.1016/j.jcv.2010.09.015

Shang, G.-S., Fang, C.-T., Liu, C.M., Wen, T. H., Tsai, K. H., and King, C. C. (2010). The role of imported cases and favorable meteorological conditions in the onset of dengue epidemics. PLoS Negl. Trop. Dis. 4, e775. doi:10.1371/journal.pntd.0000775

Shu, P. Y., Chien, L. J., Chang, S. F. Su, C. L., Kuo, Y. C., Liao, T. L. Ho, M. S., Lin, T. H., Huang, J. H. (2005). Fever screening at airports and imported dengue. Emerg. Infect. Dis. 11, 460-462.

Strait, J. A., Yang, M., Cavanaugh, J. E., and Polgreen, P. M. (2011). Upward trend in dengue incidence among hospitalized patients, United States. Emerg. Infect. Dis. 17, 914-916.

Sudiro, T. M., Zivny, J., Ishiko, H., Green, S., Vaughn, D. W., Kalayanarooj, S., Nisalak, A., Norman, J. E., Ennis, F. A., and Rothman, A. L. (2001). Analysis of plasma viral RNA levels during acute dengue virus infection using quantitative competitor reverse transcriptionpolymerase chain reaction. J. Med. Virol. 63, 29-34.

Tran, A., and Chastel, C. (2008) Mosquito-borne arboviruses and pregnancy: pathological consequences for the mother and infant. A general review. Bull. Soc. Pathol. Exot. 101, 418-424.

Vaughn, D. W., Green, S., Kalayanarooj, S., Innis, B. L., Nimmannitya, S., Suntayakorn, S., Endy, T. P., Raengsakulrach, B., Rothman, A L., Ennis, F. A., and Nisalak, A. (2000). Dengue viremia titer, antibody response pattern, and virus serotype correlate with disease severity. J. Infect. Dis. 181, 2-9.

Wagner, D., de With, K., Huzly, D., Hufert, F., Weidmann, M. Breisinger, S., Eppinger, S., Kern, W. V., and Bauer, T. M. (2004)
Nosocomial acquisition of dengue. Emerg. Infect. Dis. 10, 1872-1873.

Wang, K.-K., Chao, D.-Y., Kao, C.-L., Wu, H. C., Liu, Y. C., Li, C. M., Lin, S. C., Ho, S. T., Huang, J. H., and King, C. C. (2003). High levels of plasma dengue viral load during defervescence in patients with dengue hemorrhagic fever: implications for pathogenesis. Virology 305, 330-338.

Wilder-Smith, A., Chen, L. H., Massad, E., and Wilson, M. E. (2009). Threat of dengue to blood safety in dengue endemic countries. Emerg. Infect. Dis. 15, 8-11.

Conflict of Interest Statement: The author declares that the research was conducted in the absence of any commercial or financial relationships that could be construed as a potential conflict of interest.

Received: 22 December 2011; accepted: 12 March 2012; published online: 30 March 2012.

Citation: Chastel C (2012) Eventual role of asymptomatic cases of dengue for the introduction and spread of dengue viruses in non-endemic regions. Front. Physio. 3:70. doi: 10.3389/fphys.2012.00070

This article was submitted to Frontiers in Systems Biology, a specialty of Frontiers in Physiology.

Copyright (c) 2012 Chastel. This is an open-access article distributed under the terms of the Creative Commons Attribution Non Commercial License, which permits non-commercial use, distribution, and reproduction in other forums, provided the original authors and source are credited. 